\title{
Mayfly emergence production and body length response to hydrology in a tropical lowland stream
}

\author{
Pablo E. Gutiérrez-Fonseca ${ }^{\text {Corresp., } 1}$, Alonso Ramírez ${ }^{2}$ \\ 1 Department of Biology \& Center for Research in Marine Science and Limnology, University of Costa Rica, San José, Costa Rica \\ 2 Department of Applied Ecology, North Carolina State University, RALEIGH, NORTH CAROLINA, United States \\ Corresponding Author: Pablo E. Gutiérrez-Fonseca \\ Email address: pabloe.gutierrezfonseca@gmail.com
}

Background. Hydrological impacts on aquatic biota have been assessed in numerous empirical studies. Aquatic insects are severely affected by population declines and consequent diversity loss. However, many uncertainties remain regarding the effects of hydrology on insect production and the consequences of energy transfer to the terrestrial ecosystem. Likewise, sublethal effects on insect morphology remain poorly quantified in highly variable environments. Here, we characterized monthly fluctuation in benthic and emerged biomass of Ephemeroptera in a tropical lowland stream. We quantified the proportion of mayfly production that emerges into the riparian forest. We also examined the potential morphological changes in Farrodes caribbianus (the most abundant mayfly in our samples) due to environmental stress.

Methods. We collected mayflies (nymphs and adults) in a first-order stream in Costa Rica. We compared benthic and adult biomass from two years' worth of samples, collected with a core sampler $\left(0.006 \mathrm{~m}^{2}\right)$ and a $2 \mathrm{~m}^{2}$-emergence trap. The relationship between emergence and annual secondary production (E/P) was used to estimate the Ephemeroptera production that emerged as adults. A model selection approach was used to determine the relationship between environmental variables that were collected monthly and the emergent biomass. To determine potential departures from perfect bilateral symmetry, we evaluated the symmetry of two morphological traits (forceps and forewing) of $F$. caribbianus adults. We used Spearman's rank correlation coefficients $(\rho)$ to examine potential changes in adult body length as a possible response to environmental stress.

Results. Benthic biomass was variable, with peaks throughout the study period. However, peaks in benthic biomass did not lead to increases in mayfly emergence, which remained stable over time. Relatively constant mayfly emergence suggests that they are aseasonal in tropical lowland streams. Our E/P estimate indicated that approximately 39\% and 20\% (for 2002 and 2003, respectively) of the nymph production emerged as adults. Our estimated proportion of mayfly production transferred to terrestrial ecosystems is high relative to reports from temperate regions. We observed a strong negative response of $F$. caribbianus body length to increased hydrology (Spearman: $\rho=-0.51, p<0.001$ ), while slight departures from perfect symmetry were observed in all traits.

Conclusion. Our 2yr study demonstrates that there was large temporal variability in mayfly biomass that was unrelated to hydrological fluctuations, but potentially related to trophic interactions (e.g., fish predation). Body length was a good indicator of environmental stress, which could have severe associated costs for mayfly fitness in ecosystems with high temporal variation. Our results highlight the complex ecological and evolutionary dynamics of tropical aquatic insects, and the intricate connection between aquatic and terrestrial ecosystems. 


\section{Mayfly emergence production and body length response to hydrology in a}

\section{tropical lowland stream}

Pablo E. Gutiérrez-Fonseca ${ }^{1}$, Alonso Ramírez ${ }^{2}$

${ }^{1}$ Department of Biology \& Center for Research in Marine Science and Limnology, University of Costa Rica, San José, Costa Rica.

${ }^{2}$ Department of Applied Ecology, North Carolina State University, Raleigh, NC, USA.

Corresponding Author:

Pablo E. Gutiérrez-Fonseca ${ }^{1}$

$7^{\text {th }}$ Avenue, San José, 11501-2060, Costa Rica

Email address: pabloe.gutierrezfonseca@gmail.com

\section{Abstract}

Background. Hydrological impacts on aquatic biota have been assessed in numerous empirical studies. Aquatic insects are severely affected by population declines and consequent diversity loss. However, many uncertainties remain regarding the effects of hydrology on insect production and the consequences of energy transfer to the terrestrial ecosystem. Likewise, sublethal effects on insect morphology remain poorly quantified in highly variable environments. Here, we characterized monthly fluctuation in benthic and emerged biomass of Ephemeroptera in a tropical lowland stream. We quantified the proportion of mayfly production that emerges into the riparian forest. We also examined the potential morphological changes in Farrodes caribbianus (the most abundant mayfly in our samples) due to environmental stress.

Methods. We collected mayflies (nymphs and adults) in a first-order stream in Costa Rica. We compared benthic and adult biomass from two years' worth of samples, collected with a core sampler $\left(0.006 \mathrm{~m}^{2}\right)$ and a $2 \mathrm{~m}^{2}$-emergence trap. The relationship between emergence and annual secondary production $(\mathrm{E} / \mathrm{P})$ was used to estimate the Ephemeroptera production that emerged as adults. A model selection approach was used to determine the relationship between environmental variables that were collected monthly and the emergent biomass. To determine potential departures from perfect bilateral symmetry, we evaluated the symmetry of two morphological traits (forceps and forewing) of $F$. caribbianus adults. We used Spearman's rank 
33

34

35

36

37

38

39

40

correlation coefficients $(\rho)$ to examine potential changes in adult body length as a possible response to environmental stress.

Results. Benthic biomass was variable, with peaks throughout the study period. However, peaks in benthic biomass did not lead to increases in mayfly emergence, which remained stable over time. Relatively constant mayfly emergence suggests that they are aseasonal in tropical lowland streams. Our E/P estimate indicated that approximately 39\% and 20\% (for 2002 and 2003, respectively) of the nymph production emerged as adults. Our estimated proportion of mayfly production transferred to terrestrial ecosystems is high relative to reports from temperate regions. We observed a strong negative response of $F$. caribbianus body length to increased hydrology (Spearman: $\rho=-0.51, p<0.001$ ), while slight departures from perfect symmetry were observed in all traits.

Conclusion. Our $2 \mathrm{yr}$ study demonstrates that there was large temporal variability in mayfly biomass that was unrelated to hydrological fluctuations, but potentially related to trophic interactions (e.g., fish predation). Body length was a good indicator of environmental stress, which could have severe associated costs for mayfly fitness in ecosystems with high temporal variation. Our results highlight the complex ecological and evolutionary dynamics of tropical aquatic insects, and the intricate connection between aquatic and terrestrial ecosystems.

\section{Introduction}

Identifying factors that drive changes in natural communities has been a key issue in ecology, because it allows us to understand current patterns and to predict community responses to environmental change (Power et al., 1988; Resh et al., 1988). In freshwater ecosystems, much attention is given to understand the impact of environmental variables on aquatic organisms at multiple levels, from individuals to the community (e.g., Ardón et al., 2013; Klem \& GutiérrezFonseca, 2017). Among a wide range of factors, hydrology has often been reported as most prominent affecting aquatic biota (Ramírez \& Pringle, 1998; Ríos-Touma, Encalada \& Prat Fornells, 2011). Thus, while it is well known that hydrology reduces populations by catastrophic mortality, channel scouring, and resource redistribution; we know less about sublethal stresses that elicit escape (e.g., early emergence) or generate morphological changes.

Insect emergence can be used as a reliable indicator of population success as it reflects the influence of multiple environmental stressors that populations face during their larval development. Temporal patterns of insect emergence are often synchronized and occur during a 
65 limited period of time (e.g., Castro-Rebolledo \& Donato-Rondon, 2015). However, hydrology

66 may strongly affect seasonality, magnitude, and timing of emergence (Whiles \& Goldowitz,

67 2001; Lytle, 2002). This can have negative effects in aquatic-terrestrial energy fluxes, since

68 emerged aquatic insects provide significant subsidies for riparian food webs (Nakano \&

69 Murakami, 2001). Thus, although emergent biomass may be a small fraction of benthic biomass

70 (Statzner \& Resh, 1993), changes in the number and morphology (e.g., body length) of

71 individuals can have a large impact on the biomass and nutrient export to adjacent terrestrial

72 ecosystem (Small et al., 2013a; Kelly, Cuevas \& Ramírez, 2015).

73 Individual body length and deviation from perfect bilateral symmetry are particularly

74 useful as measures of developmental stability (i.e., ability of an individual to adequately buffer

75 its developmental processes against environmental and genetic perturbations and ensure common

76 developmental outcomes under particular ecological and evolutionary conditions).

77 Environmental stressors affect body length by affecting growth or development rates, which

78 carries significant consequences for individual fitness and alters mortality rates and reproductive

79 success (Peckarsky et al., 2001; Dahl \& Peckarsky, 2003). Bilateral symmetry is known for

80 many traits, and departure from symmetrical phenotypes has been linked to low success of

81 individuals in sexual competition (Møller, 1990; Santos, 2001; Jorge \& Lomônaco, 2011).

82 Departures from symmetry are commonly grouped into three categories, based on frequency

83 distributions of the differences between the right and left sides of a structure: a) directional

84 asymmetry (i.e., greater development of a character on one side), b) antisymmetry (i.e.,

85 asymmetry without directional bias), and c) fluctuating asymmetry (i.e., random departure from

86 perfect symmetry of any bilateral anatomical character, showing a normal distribution with a

87 mean of zero). The first two cases of asymmetry are related to heritable variation for asymmetry,

88 while fluctuating asymmetry is commonly caused by environmental disturbance (Palmer \&

89 Strobeck, 1986, 1992).

90 Tropical streams are highly variable in their environmental parameters, which has an

91 influence on aquatic biota (Jacobsen \& Encalada, 1998; Ramírez, Pringle \& Douglas, 2006).

92 Streams draining humid tropical rainforests often experience unpredictable hydrological events,

93 which may represent sources of stress to aquatic populations. This is especially true for tropical

94 mayflies, which may live relatively long-periods in the streams (range from 26 to 165 days,

95 Sweeney, Jackson, \& Funk, 1995) compared to their lifespan as adults (range from 3 to 6 days, 
96 Vásquez, Flowers, \& Springer, 2009). Streams at La Selva Biological Station (LSBS) offer an

97 excellent opportunity to assess how environmental stressors influence aquatic biota, as they show

98 high interannual variability in their environmental variables (Ramírez, Pringle \& Douglas, 2006;

99 Small et al., 2012; Gutiérrez-Fonseca, Ramírez \& Pringle, 2018).

100 In this study, we examine the benthic and emerged biomass of Ephemeroptera in a small

101 tropical lowland stream. We quantified the biomass transfer to the terrestrial ecosystem by adult

102 emergence production (i.e., E/P ratio). We also assess whether environmental variability can

103 influence mayfly morphology (i.e., symmetry and body length). We approach our objectives in

104 four ways: first, we used data collected during two years (2002-2003) to determine temporal

105 patterns of emerged Ephemeroptera and the benthic standing-stock biomass. Then, we estimated

106 the E/P using adult biomass and nymph secondary production for each year. Second, we

107 identified which environmental variables are related to the emergence patterns of mayflies.

108 Third, we examined departures from perfect symmetry in adults of the Leptophlebiidae Farrodes

109 caribbianus (Traver) comb. nov. (Domínguez, 1999), the most abundant Ephemeroptera found in

110 our emergence trap. Fourth, we assessed potential changes in body length of $F$. caribbianus and

111 how they relate to the variation in rainfall. We focus on precipitation as a key factor impacting

112 macroinvertebrates, since previous studies have demonstrated their influence on LSBS streams

113 (Ramírez, Pringle \& Douglas, 2006; Gutiérrez-Fonseca, Ramírez \& Pringle, 2018). We

114 hypothesized large mayfly mortality due to drag forces experienced by individuals during floods,

115 as well as an increase in nymph development instability due to exposure to environmental

116 stressors during their lifespan. We expected to observe a peak in benthic and emergent biomass

117 during the low rainfall season, as well as changes in adult symmetry and body length.

118

119 Materials \& Methods

120 Study system

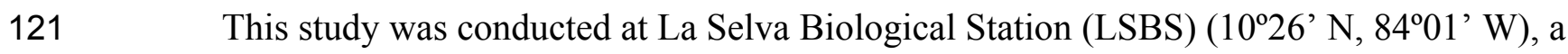

1221563 ha reserve in the Caribbean slope of Costa Rica, located in a gradient break between the

123 Cordillera Central and the coastal plain. The forest in LSBS is composed of mature and

124 secondary tropical rainforest (Holdridge, 1967). Long-term average annual precipitation (1963-

125 2016) is $4354 \mathrm{~mm}$, ranging from $2809 \mathrm{~mm}$ in 1995 to $6165 \mathrm{~mm}$ in 1970 (available at

$126 \mathrm{http}: / /$ www.ots.ac.cr/meteoro/). The annual distribution is bimodal, with peaks of $>400 \mathrm{~mm} / \mathrm{mo}$ 
127 occurring both in June-July and November-December. The period with low rainfall values is 128 February-April (Sanford et al., 1994).

129 We collected the Ephemeroptera samples (nymphs and adults) from Carapa, a first order 130 stream ( $1 \mathrm{~m}$ wide and $0.25 \mathrm{~m}$ deep) bordered with abundant riparian vegetation (canopy cover: $13185 \%$, Small et al., 2013b). We obtained the samples from an approximately $100 \mathrm{~m}$ reach, which 132 was representative of overall stream conditions. Within the study reach, channel substrate type 133 was consistently dominated by detritus and fine sediments (i.e., silt and clay). Long-term data 134 sets (1997-2011) show that discharge ranges from 0.011 to $0.027 \mathrm{~m}^{3} / \mathrm{s}$, stream temperature from 13521.4 to $27.2{ }^{\circ} \mathrm{C}$ and $\mathrm{pH}$ from 3.62 to 6.46 , with low values occurring during the El Niño event of 136 1997-1998 (Small et al., 2012; Gutiérrez-Fonseca, Ramírez \& Pringle, 2018).

137 Benthic macroinvertebrate assemblages in Carapa are diverse, and include several species 138 of dipterans, mayflies, caddisflies, odonates, beetles, and non-insects. Diptera dominates the 139 taxonomic richness, abundance, and biomass of insects. Odonata, Trichoptera, and 140 Ephemeroptera are also numerically important groups (Ramírez, Pringle \& Douglas, 2006; 141 Gutiérrez-Fonseca, Ramírez \& Pringle, 2018). Fish assemblages are dominated by the 142 insectivorous fish Priapicthys annectens (98\% of abundance, Family Poeciliidae) (Small et al., 143 2013b).

\section{Nymph biomass and production}

We used data of mayfly benthic standing-stock biomass from Gutiérrez-Fonseca,

147 Ramírez and Pringle (2018). Ephemeroptera nymphs were sampled monthly for two years (2002-

148 2003). Three core samples $\left(0.006 \mathrm{~m}^{2}\right.$ each $)$ were collected in runs with leaves as the dominant substrate. All material enclosed into the core was removed to a depth of $\sim 10 \mathrm{~cm}$ or until reaching bedrock. Mayfly nymphs were removed from organic matter and preserved in $80 \%$ ethanol. Biomass of individual nymphs was estimated by applying the length-mass relationship developed by Benke et al. (1999), expressed as ash-free dry mass (AFDM) per area $\left(\mathrm{m}^{2}\right)$. collected in our study, as we did not find nymphs of all size classes on all sampling dates. Instead, we estimated P using the production-to-biomass (P/B) method (Benke, 1993). An average P/B value for Ephemeroptera at La Selva $\left(13.63 \mathrm{y}^{-1}\right)$ was obtained from Ramírez \& 
158 method, it should provide us with the best approximation given our limited information on 159 tropical Ephemeroptera.

160

\section{Adult emergence and biomass}

We used a $2 \mathrm{~m}^{2}$ (sampling area) emergence trap (BioQuip Products, Rancho Dominguez,

163

164

165

166

167

168

169

170

171

172

173

174

175

176

177

178

179

180

181

182

183

184

185

186

187

188

California) to sample mayfly adults continuously from July 2001 to February 2004. The trap was suspended over the stream and covered the entire stream width, which allowed us to sample in various microhabitats such as riffles, pools, runs and stream banks. Emerging insects were collected weekly and preserved in $80 \%$ ethanol for subsequent taxonomic identification. A modified handheld vacuum was used to remove emergent insects from the trap. The trap was inspected often for maintenance (i.e., repair of holes and removal of spider webs). Mayfly biomass was calculated by measuring the length of each individual and applying the length-mass relationship developed by Sabo et al. (2002). Emergence biomass was expressed as mg AFDM $\mathrm{m}^{2}$ by taking the total biomass of each month adjusted by the trap area. Total annual biomass was determined by adding all weekly samples for each year.

\section{Physicochemical variables and hydrology}

We measured eight physicochemical variables monthly, simultaneously with Ephemeroptera collections. Nutrient concentrations (i.e., $\mathrm{NO}_{3}{ }^{-}-\mathrm{N}, \mathrm{NH}_{4}{ }^{+}-\mathrm{N}$ and $\mathrm{PO}_{4}{ }^{3-}-\mathrm{P}$ as soluble reactive P: SRP) were measured by collecting 2 filtered ( $0.45 \mu \mathrm{m}$ Millipore filters) water samples using new $125 \mathrm{~mL}$ bottles. Samples were kept frozen until analyzed. $\mathrm{NO}_{3}{ }^{-} \mathrm{N}, \mathrm{NH}_{4}{ }^{+} \mathrm{N}$, and SRP concentrations were measured using continuous-flow colorimetry and an Alpkem RFA 300 colorimetric analyzer. We used cadmium-reduction, phenol-hypochlorite, and ascorbic acid methods for $\mathrm{NO}_{3}{ }^{-}-\mathrm{N}, \mathrm{NH}_{4}{ }^{+}-\mathrm{N}$, and SRP, respectively (APHA, 1998). We measured stream temperature, $\mathrm{pH}$, and conductivity in situ with a handheld meter (Hanna Instruments, Woonsocket, Rhode Island). The stream flow was measured with a Marsh-McBirney current meter (Marsh McBirney Inc., Frederick, Maryland), and discharge was calculated using the velocity-area method (Gordon et al., 2004). Monthly precipitation was recorded using data from the meteorological station available at LSBS (OTS meteorological data, http://www.ots.ac.cr/meteoro/). 
189 Measurement of traits and body length of $\boldsymbol{F}$. caribbianus

190 We measured the body length (not including cerci) of all individual mayflies to quantify 191 size variation patterns. To determine departures from symmetry, we measured the length of the 192 second segment of forceps (SF) on the right and left sides of males, as well as forewing area 193 (AFW) and forewing length (LFW) on the right and left sides of both males and females. Body 194 parts were removed with forceps, mounted on glass slides, and photographed with a 195 stereomicroscope (AmScope) and a microscope (Nikon Eclipse E400). Images were analyzed 196 with the free computer software ImageTool 2.0 (University of Texas Health Science Center, San 197 Antonio). All linear and area measurements were done with an accuracy of $0.01 \mathrm{~mm}$ and 0.01 $198 \mathrm{~mm}^{2}$, respectively. To avoid mistaking human error with potential asymmetries, we used one 199 image per individual to take three non-consecutive (i.e., in a random order) measurement of each 200 trait.

201

\section{Data analyses}

203 We used biomass to compare temporal patterns between benthic and emerging mayflies, 204 since biomass better reflects potential changes in production driven by environmental variability, 205 beyond other metrics such as abundance and diversity (Malison, Benjamin \& Baxter, 2010).

206 Likewise, biomass estimates are widely used in analyses of food webs and secondary production.

207 To estimate the fraction of Ephemeroptera production that emerged as an adult and was exported 208 to riparian ecosystems, we calculated the ratio of adult emergence to nymph secondary 209 production $(\mathrm{E} / \mathrm{P})$ for each year.

210 A model selection approach based on Akaike's Information Criteria (AIC, Akaike, 1973)

211 was used to identify the best-fit model that included the environmental variables influencing 212 adult mayfly biomass. Model constructions and selections are described in more detail in 213 Gutiérrez-Fonseca, Ramírez and Pringle (2018). Briefly, we build linear regression models using 214 a forward selection procedure. We identified the model with the best quality (i.e., with a 215 minimum number of required explanatory variables) based on the lowest AICc $(<2 \Delta)$. Model 216 averaging was used to draw conclusions when more than one model was included in the subset. 217 Multicollinearity among variables was assessed by calculating the variance inflation factor 218 (VIF). Environmental variables with a VIF>10 were identified and removed from the analysis 
219 (O'Brien, 2007). Before building the models, we also excluded variables that were highly 220 correlated $(|\mathrm{r}|>0.60)$.

221 To examine the association between body length and hydrology, we first related monthly 222 average precipitation to discharge using Pearson correlation coefficients. Then, we determined 223 the relationship between body length and average precipitation in the 159 days before collecting 224 the emergence trap using non-parametric Spearman's rank correlation coefficients, due to the 225 non-normal distribution of the data. Spearman's rank correlations were calculated separately for 226 males $(\mathrm{n}=67)$, females $(\mathrm{n}=50)$ and both sexes combined $(\mathrm{n}=117)$. We used average precipitation 227 of the 159 days, as this timeframe coincides with the life cycle of Thraulodes sp. (same family, 228 Leptophlebiidae), which was estimated as the median days since an egg hatches until the 229 individual reaches adulthood (Jackson \& Sweeney, 1995).

230 Analyses of potential departure from symmetry were performed on approximately 30 231 randomly selected individuals for each test, following the procedure recommended by Palmer 232 and Strobeck $(1986,2003)$ and Palmer (1994). We used the signed differences between right and 233 left $(\mathrm{R}-\mathrm{L})$ to distinguish fluctuating asymmetry (must be normally distributed with zero mean) 234 from antisymmetry and directional symmetry. The Shapiro-Wilks test was used to determine 235 whether the data were normally distributed, which would rule out antisymmetry. Directional 236 asymmetry is characterized by a normal distribution with a mean other than zero. Therefore, we 237 also conducted one-sample $t$-tests to determine if the mean of signed $(\mathrm{R}-\mathrm{L})$ differed statistically 238 from zero.

Analysis of potential fluctuating asymmetries were conducted for each trait using three 240 indices recommended by Palmer and Strobeck (2003): FA1, FA4a, and FA10a. FA1, calculated 241 as mean of $|\mathrm{R}-\mathrm{L}|$, is the recommended index because it is easy to understand. FA4a $(0.798$ $242 \sqrt{ } \operatorname{var}(\mathrm{R}-\mathrm{L})$ ) has higher statistical power and represents the contribution of FA measurement error. 243 The FA10 index describes the average difference between sides after measurement error has 244 been partitioned out. This index was calculated using two-way mixed model ANOVAs with side 245 (Fixed), individual (Random) and their interaction (Side $x$ Individual). Then, we used the mean 246 square (ME) to calculate FA10 as $0.798 \sqrt{ } 2 \sigma_{\mathrm{i}}^{2}$ (where $\sigma_{\mathrm{i}}^{2}=\mathrm{ME}_{\mathrm{SxI}}-\mathrm{ME}_{\text {error }}$ ). Additionally, we 247 calculated measurement error as a percentage (ME3, according to Palmer \& Strobeck, 2003) by $248 \mathrm{ME}_{\text {error }} / \mathrm{ME}_{\mathrm{SxI}} \times 100$. ME3 represents the mean difference between replicate measurements as a 249 proportion of mean difference between of the sides $\mathrm{x}$ individual interaction. 
251 function of the stats package, the two-way mixed model ANOVA with the lmer() function of the 252 lme4 package (Bates et al., 2015), model averaging with the AICcmodavg package (Mazerolle, 253 2019) and graphics were produced using the ggplot2 package (Wickham, 2016) in R version 254 3.6.3 (R Core Team, 2019). Raw data and code used in this study are available on a GitHub 255 repository: https://github.com/PEGutierrezF/mayfly_morphometry.

256

\section{Results}

Precipitation and hydrology

259

Monthly total precipitation showed a strong seasonal pattern during the study period.

The dry season had the lowest precipitations in March 2002 (140.8 mm) and April 2003 (45.3

261

$\mathrm{mm})$. The wet season had maximum values in May $2002(890.8 \mathrm{~mm})$ and December 2003

262 $(561.3 \mathrm{~mm})$ (Fig. 1A). Discharge reflected the monthly average precipitation variability in the two years of sampling (Pearson: $r=0.64, p<0.001$, Fig. 1B).

264

Figure 1. Temporal variability of precipitation in 2002 and 2003 (A), and relationship between 266 mean monthly precipitation and discharge (B). Grey shaded area represents the $95 \%$ confidence intervals.

268

\section{Benthic and emergence biomass, and E/P patterns}

Mean annual biomass of nymphs was $1.74 \mathrm{mg} \mathrm{AFDM} / \mathrm{m}^{2}$ in 2002 and $2.22 \mathrm{mg}$

271 $\mathrm{AFDM} / \mathrm{m}^{2}$ in 2003. Benthic biomass peaked in March, July, and September 2002, and January, and October 2003 (Fig. 2). Meanwhile, mean annual biomass of emerging adults was $0.76 \mathrm{mg}$ $\mathrm{AFDM} / \mathrm{m}^{2}$ in 2002 and $0.50 \mathrm{mg} \mathrm{AFDM} / \mathrm{m}^{2}$ in 2003. Monthly mayfly emergence was relatively constant throughout the study periods compared to benthic biomass, except for a slight increase in June 2002 (Fig. 2A). Total emergence was $9.14 \mathrm{mg} \mathrm{AFDM} \mathrm{m}^{-2} \mathrm{y}^{-1}$ and $5.99 \mathrm{mg} \mathrm{AFDM} \mathrm{m}^{-2} \mathrm{y}^{-}$ represented $38.57 \%$ and $19.78 \%$ of nymph secondary production for 2002 and 2003 , respectively. 
281 Figure 2. Temporal variability of benthic and emerging adult biomass during (A) 2002 and (B) 2822003.

\section{Physicochemical characteristics and individual-level variation}

284 The AIC analysis used to determine the relative importance of environmental variables 285 on the biomass of emerging adults showed no support for any model. Therefore, none of the 286 variables related to nutrients, hydrology or physicochemistry that were evaluated in our study 287 explained the relatively constant patterns of mayfly emergence in our streams.

Body length of $F$. caribbianus was strongly influenced by average rainfall during the 159 289 days of nymph development. Spearman's rank correlations revealed a negative relationship between average rainfall and body length of males (Spearman: $\rho=-0.45, p<0.001$ ), females (Spearman: $\rho=-0.64, p<0.001$ ), and both sexes combined (Spearman: $\rho=-0.51, p<0.001$, Fig. $3)$.

293

Figure 3. Body length variability of $F$. caribbianus and precipitation.

295 Relationship between $F$. caribbianus body length and average precipitation in the 159 days prior

296 to the sampling date. Each point represents an individual, including males and females. Gray shaded area represents the $95 \%$ confidence intervals.

Fluctuating asymmetry analysis in $F$. caribbianus

A total of $117 \mathrm{~F}$. caribbianus (50 females and 67 males) were assessed (in groups of $\sim 30$ randomly selected individuals for each test) to determine departure from symmetry. Analyses of trait value distribution satisfied the assumption of normality, so there was no evidence of antisymmetry in any of the characters ( $p>0.05$, Table 1$)$. Also, the $t$-tests revealed that mean (R305 L) was not significantly different from zero, which suggests that there was no directional asymmetry $(p>0.05$, Table 1$)$.

306

Table 1. Test for normality and $t$-test for each trait. AFW: forewing area, LFW: forewing length; 308 SF: length of the second segment of forceps.

309 was always significant, while global error $\left(\mathrm{ME}_{\text {error }}\right)$ was found to be smaller than the error of the interaction $\left(\mathrm{ME}_{\mathrm{SxI}}\right)$ for all traits. Measurement error $\left(\mathrm{ME3}: \mathrm{M}_{\mathrm{error}} / \mathrm{ME}_{\mathrm{SxI}} \mathrm{X} 100\right)$ contributed 5.9- 
$31319.6 \%$ of the total variance between-sides for each trait, which indicates that $\sim 80 \%$ of the 314 measurement variation was reliable. Fluctuating asymmetries for each trait amounted to roughly $3151.07 \%-2.67 \%$ of the average size of the corresponding trait (FA1/mean). The estimates for 316 FA4a and FA10a varied from 0.013 to 0.088 and from 0.002 to 0.034 , respectively.

317

318 Table 2. Result of the two-way mixed model ANOVAs performed for each trait with Side as a 319 Fixed component and Individual as Random component.

320 Indices of asymmetry: FA1, FA4a, FA10a and measurement error as percentage (ME3 as \% of $\left.321 \mathrm{ME}_{\mathrm{SxI}}\right)$. AFW: forewing area, LFW: forewing length, SF: length of the second segment of 322 forceps.

$323 * \mathrm{p}<0.05$; ${ }^{\text {a }}$ mean of the standard deviation of triplicate measurements on the right and left sides 324 (i.e., indicator of accuracy during photo measurement); ${ }^{b}$ mean of the right and left side 325 measurements; ${ }^{\mathrm{C}}$ mean squared of the side $\times$ individual interaction; ${ }^{\mathrm{d}}$ mean squared of the 326 variance of the repeated measurements.

327

328

329

330

331

332

333

334

335

336

337

338

339

340

341

342

343

\section{Discussion}

Our two-year study showed high temporal variability of mayfly benthic biomass, characterized by multiple peaks during the study period. Unexpectedly, these peaks in benthic biomass did not translate into measurable increases in emerging adult biomass, which represented a small fraction of the benthic biomass. Notably, while benthic and emergent biomass were similar during most of the study period, the observed peaks in nymph biomass were not associated to similar peaks in the emergence of adults. Peaks in benthic biomass occurred in different periods of the year, which may suggest that different mechanisms control population dynamics of benthic and emerging mayflies. E/P ratio varied between $38.57 \%$ in 2002 and 19.78\% in 2003, and was higher than reports in previous studies for emerging aquatic insects in temperate regions. We did not observe a relationship between hydrology and the biomass of benthic and emergent mayflies, so our expectation that mayfly biomass would peak in the dry season of La Selva was not supported by our findings. Looking more closely at $F$. caribbianus, the most abundant mayfly collected in emergence traps, we found no evidence of antisymmetry or directional symmetry, but we did find slight deviations from symmetry that were larger than measurement errors, suggesting alterations in bilateral morphology of $F$. 
344 caribbianus. We also found a strong negative relationship between body length and precipitation

345 variability at La Selva. This relationship was consistently significant for males, females, and both 346 sexes combined.

347 Our E/P estimation indicated that less than $40 \%$ (38.57\% and $19.78 \%$ for 2002 and 2003 , 348 respectively) of nymph secondary production was exported to the terrestrial ecosystem. This 349 potentially low value may have negative consequences on the riparian food web, as emerging 350 insects represent an important source of energy and nutrients in La Selva streams (N-flux: 0.40$1.25 \mathrm{mg} \mathrm{N} \mathrm{m}^{-2} \mathrm{~d}^{-1}$, Small, Duff, et al. 2013). Surprisingly, our E/P estimates were equal to, or 352 exceeded, the values previously reported for single groups of aquatic insects, such as $19.3 \%$ for Hydropsyche angustipennis and $27 \%$ for $H$. pellucidula (Trichoptera) in a Northern German

354 355 356 357 358

359 360 361 362 363 364 365 366 367 368 369 lowland stream (Poepperl, 2000a), and 16\% for a limnephilid (Trichoptera) in an intermittent wetland (Whiles, Goldowitz \& Charlton, 1999). Our E/P estimates were also high when compared to entire insect assemblages, such as $16.6 \%$ in desert streams (Jackson \& Fisher, 1986) and $18.3 \%$ in a northern German stream (Poepperl, 2000b). Our E/P estimates even exceed the biomass export of aquatic vertebrates, such as salamanders $(10 \%$, Regester, Lips \& Whiles, 2006). These elevated E/P ratios may be explained by the warm water temperatures (range: 21.4 to $27.2{ }^{\circ} \mathrm{C}$, Gutiérrez-Fonseca, Ramírez \& Pringle, 2018), and high biomass turnover rates of fast-growing mayflies $(\mathrm{P} / \mathrm{B}=13.63$, Ramírez \& Pringle, 1998) that are characteristic of many tropical streams.

Unlike the large fluctuations in emergence patterns observed in other studies (Masteller, 1993; Pescador, Masteller \& Buzby, 1993; Castro-Rebolledo \& Donato-Rondon, 2015; Yuen \& Dudgeon, 2016), providing support for seasonality in many tropical aquatic insects, the lack of abrupt peaks in mayfly emergence found in our study suggests that mayfly emergence is aseasonal. Fish predation on newly emerged adults may be a possible explanation for the constant biomass of emerging mayflies in our study. Our focal stream is inhabited by the insectivorous poeciliid, P. annectens, which is abundant (4-14 individuals $/ \mathrm{m}^{2}$, Small et al. 2013) and could have negatively affected mayfly emergence. Previous studies have shown a reduction of total emergence biomass of aquatic insects by $62 \pm 8 \%$ (Merkley, Rader $\&$ Schaalje, 2015) and 65\% (Warmbold \& Wesner, 2018) in mesocosms with a similar fish density (11.4 fish $/ \mathrm{m}^{2}$ and $7.8 \mathrm{fish} / \mathrm{m}^{2}$, respectively) to our study stream. Field studies have also found that fish can regulate the timing and duration of aquatic insect emergence (Moore \& Schindler, 2010). 
375 Therefore, it is not surprising for biotic control to be an important factor controlling insect

376 emergence in our tropical lowland streams, which harbor high fish diversity.

$377 \quad$ Hydrology has been recognized as a key factor controlling macroinvertebrate

378 assemblages in tropical streams (Flecker \& Feifarek, 1994; Ramírez \& Pringle, 1998; Molineri,

379 2010), with peaks in biomass expected during the dry season and high mortality during the rainy

380 season. However, we observed peaks in benthic biomass during both the dry and rainy seasons

381 in La Selva. Peaks during the rainy season might be caused by microdistributional changes in

382 macroinvertebrates driven by high floods (Lancaster \& Hildrew, 1993; Lancaster, 1999). For

383 instance, mayflies have been observed to make small-scale refuge-seeking movements between

384 substrate layers during simulated floods (Holomuzki \& Biggs, 2000). This type of mechanisms

385 could allow for high mayfly survival in streams such as Carapa, where the deep subsurface layers

386 may provide shelter and protection for insects year round, as proposed for similar streams

387 (Holomuzki \& Biggs, 2000).

388 Our results show a strong influence of precipitation on the total body length of $F$.

389 caribbianus. Large individuals were negatively affected by precipitation, while small-sized

390 mayflies persisted during high rainfall events (Fig. 3). In tropical streams, two mechanisms have

391 been identified as potential ways in which insects respond to catastrophic floods. The first

392 mechanism proposes that small-sized individuals have better chances of surviving floods by

393 finding refuge in interstitial spaces (Townsend, Dolédec \& Scarsbrook, 1997; Segura, Siqueira \&

394 Fonseca-Gessner, 2013). The second hypothesis suggests that some aquatic insects (e.g.,

395 Odonata: Polythoridae) emerge, copulate and oviposit at the onset of the rainy season, so that

396 only small larvae (which can be protected by large logs and rocks) are present during periods of

397 frequent floods (Pritchard, 1996). Since mayflies in La Selva are multivoltine (Ramírez \&

398 Pringle, 1998), we find more support for the first hypothesis through this study.

Asymmetrical traits have been used successfully as an early warning biomarker related to 400 developmental stress (Graham et al., 2010). Common stress sources that cause fluctuating 401 asymmetries in aquatic insects include water quality (Bonada \& Williams, 2002), insecticide 402 (Mpho, Holloway \& Callaghan, 2001), experimental food deprivation (Nosil \& Reimchen, 2007) 403 and changes in the physical structure of riparian vegetation (Pinto et al., 2012). We found slight 404 variations from perfect symmetry in the wings and forceps of $F$. caribbianus, which suggests 405 some level of developmental instability of the nymph. However, given the limited number of 
406 mayflies per period, we were unable to perform analyses under different levels of environmental 407 stressors (e.g., low, medium, and high hydrology). Therefore, although we found slight random 408 deviations from symmetry, they are not distinguishable from developmental noise (i.e., random 409 variation from symmetry caused by metabolic rates, concentrations of regulatory molecules, 410 diffusion, or thermal noise) without further study (Palmer \& Strobeck, 2003).

411 Future climate change scenarios predict an increase in hydrological extreme events for 412 many regions (Christensen et al., 2013). Extreme precipitation events are expected to increase in 413 tropical regions (O’Gorman \& Schneider, 2009), with potential negative effects on aquatic biota 414 and aquatic-terrestrial linkages. Increases in heavy precipitation events have already been 415 observed in the Caribbean slope of Costa Rica during the last decades (Aguilar et al., 2005; Rapp 416 et al., 2014; Sánchez-Murillo et al., 2017), where climate projections suggest an increase in mean 417 annual precipitation of between 10 to 50\% (Alvarado et al., 2012). Therefore, large hydrological 418 variability can threaten the fitness of mayfly populations in La Selva, as well as in other tropical 419 regions.

420

\section{Conclusions}

422 Contrary to our expectations and patterns shown in literature, we found a lack of seasonality in 423 benthic biomass. Adult biomass was unrelated to peaks in benthic biomass, which makes us 424 wonder what is controlling adult biomass export in these systems if not hydrology (e.g. fish 425 predation). Based on our E/P ratios, Neotropical streams can provide larger subsidies to adjacent 426 terrestrial ecosystems than their counterparts in temperate regions. Departures from perfect 427 symmetry were evident in all the evaluated traits, which suggests developmental instability of 428 mayflies. Body length proved to be a better indicator of environmental stress, which could have 429 severe associated costs for mayfly fitness in ecosystems with high temporal variation. Further 430 research could quantify effects of body length reduction in mayfly fitness, energy and nutrient 431 export to riparian food webs, as well as the role of biotic control on mayfly biomass in tropical 432 lowland streams.

433

\section{Acknowledgements}

We are grateful to Minor Hidalgo for his invaluable assistance in collecting benthic and 436 adult samples. Thanks also to Eduardo Domínguez for identifying the Farrodes species, José A. 
437 Sánchez-Ruiz for his assistance in the laboratory, and Aura M. Alonso-Rodríguez for revising 438 earlier drafts of the manuscript. We thank to Organization for Tropical Studies and the staff of 439 La Selva Biological Station for their help in facilitating this research.

440

441

442

443

444

445

446

447

448

449

450

451

452

453

454

455

456

457

458

459

460

461

462

463

464

465

466

467

\section{References}

Aguilar E, Peterson TC, Ramírez Obando P, Frutos R, Retana JA, Solera M, Soley J, González García I, Araujo RM, Rosa Santos A, Valle VE, Brunet M, Aguilar L, Álvarez L, Bautista M, Castañón C, Herrera L, Ruano E, Sinay JJ, Sánchez E, Hernández Oviedo GI, Obed F, Salgado JE, Vázquez JL, Baca M, Gutiérrez M, Centella C, Espinosa J, Martínez D, Olmedo B, Ojeda Espinoza CE, Núñez R, Haylock M, Benavides H, Mayorga R. 2005. Changes in precipitation and temperature extremes in Central America and northern South America, 1961-2003. Journal of Geophysical Research Atmospheres 110:D23107. DOI: 10.1029/2005JD006119.

Akaike H. 1973. Information theory and an extension of the maximum likelihood principle. In: Petrov BN, Csáki F eds. 2nd International Symposium on Information Theory, Tsahkadsor, Armenia, USSR. Budapest: Akadémiai Kiadó, 267-281.

Alvarado LF, Contreras W, Alfaro M, Jiménez E. 2012. Escenarios de cambio climático regionalizados para Costa Rica. San Jose, Costa Rica: Departamento de Climatología e Investigaciones Aplicadas del IMN, MINAET.

APHA. 1998. Standard Methods for the Examination of Water and Wastewater. Washington, D.C.: American Public Health Association.

Ardón M, Duff JH, Ramírez A, Small GE, Jackman AP, Triska FJ, Pringle CM. 2013. Experimental acidification of two biogeochemically-distinct neotropical streams: Buffering mechanisms and macroinvertebrate drift. Science of the Total Environment 443:267-277. DOI: 10.1016/j.scitotenv.2012.10.068.

Bates D, Mächler M, Bolker BM, Walker SC. 2015. Fitting linear mixed-effects models using lme4. Journal of Statistical Software 67. DOI: 10.18637/jss.v067.i01.

Benke AC. 1993. Concepts and patterns of invertebrate production in running waters. Verhandlungen der Interna- tionalen Vereinigung fur Theorestische und Angewandte Limnologie 25:15-38. DOI: 10.1080/03680770.1992.11900056. 
468 Benke AC, Huryn AD, Smock LA, Wallace JB. 1999. Length-mass relationships for freshwater

469

470

471

472

473

474

475

476

477

478

479

480

481

482

483

484

485

486

487

488

489

490

491

492

493

494

495

496

497

498

macroinvertebrates in North America with particular reference to the Southeastern United States. Journal of the North American Benthological Society 18:308-343. DOI: $10.2307 / 1468447$

Bonada N, Williams DD. 2002. Exploration of the utility of fluctuating asymmetry as an indicator of river condition using larvae of the caddisfly Hydropsyche morosa (Trichoptera: Hydropsychidae). Hydrobiologia 481:147-156. DOI: 10.1023/A:1021297503935.

Castro-Rebolledo MI, Donato-Rondon JC. 2015. Emergence patterns in tropical insects: The role of water discharge frequency in an Andean Stream. Annales de Limnologie 51:147-155. DOI: $10.1051 / \mathrm{limn} / 2015011$.

Christensen JH, Kanikicharla KK, Aldrian E, An SI, Cavalcanti IFA, de Castro M, Dong W, Goswami P, Hall A, Kanyanga JK, Kitoh A, Kossin J, Lau NC, Renwick J, Stephenson DB, Xie SP, Zhou T. 2013. Climate phenomena and their relevance for future regional climate change. In: Stocker TF, Qin D, Plattner G-K, Tignor M, Allen SK, Boschung J, Nauels A, Xia Y, Bex V and, Midgley PM eds. Climate Change 2013: The Physical Science Basis: Working Group I. Contribution to the Fifth Assessment Report of the Intergovernmental Panel on Climate Change. Cambridge, United Kingdom and New York, NY, USA: Cambridge University Press, 1217-1308. DOI: 10.1017/CBO9781107415324.028.

Dahl J, Peckarsky BL. 2003. Developmental responses to predation risk in morphologically defended mayflies. Oecologia 137:188-194. DOI: 10.1007/s00442-003-1326-0.

Domínguez E. 1999. Systematics, cladistics and biogeography of the American genus Farrodes (Ephemeroptera: Leptophlebiidae: Atalophlebiinae). Zoological Journal of the Linnean Society 126:155-189. DOI: 10.1111/j.1096-3642.1999.tb00152.x.

Flecker AS, Feifarek B. 1994. Disturbance and the temporal variability of invertebrate assemblages in two Andean streams. Freshwater Biology 31:131-142. DOI: 10.1111/j.1365-2427.1994.tb00847.x.

Gordon ND, Mcmahon TA, Finlayson BL, Gippel CJ, Nathan RJ. 2004. Stream hydrology: an introduction for ecologists. West Sussex, England: John Wiley and Sons Ltd.

Graham JH, Raz S, Hel-Or H, Nevo E. 2010. Fluctuating asymmetry: methods, theory, and applications. Symmetry 2:466-540. DOI: 10.3390/sym2020466.

Gutiérrez-Fonseca PE, Ramírez A, Pringle CM. 2018. Large-scale climatic phenomena drive

Peer) reviewing PDF | (2020:03:47058:2:0:NEW 10 Aug 2020) 
499

500

501

502

503

504

505

506

507

508

509

510

511

512

513

514

515

516

517

518

519

520

521

522

523

524

525

526

527

528

529

fluctuations in macroinvertebrate assemblages in lowland tropical streams, Costa Rica: The importance of ENSO events in determining long-term (15y) patterns. PLOS ONE 13:e0191781. DOI: 10.1371/journal.pone.0191781.

Holdridge LR. 1967. Life zone ecology. Tropical Science Center.

Holomuzki JR, Biggs BJF. 2000. Taxon-specific responses to high-flow disturbance in streams:implications for population persistence. Journal of the North American Benthological Society 19:670-679. DOI: 10.2307/1468125.

Jackson JK, Fisher SG. 1986. Secondary production, emergence, and export of aquatic insects of a Sonoran Desert stream. Ecology 67:629-638. DOI: 10.2307/1937686.

Jackson JK, Sweeney BW. 1995. Egg and larval development times for 35 species of tropical stream insects from Costa Rica. Journal of the North American Benthological Society 14:115-130. DOI: $10.2307 / 1467728$.

Jacobsen D, Encalada A. 1998. The macroinvertebrate fauna of Ecuadorian highland streams in the wet and dry season. Archiv fur Hydrobiologie 142:53-70.

Jorge AS, Lomônaco C. 2011. Ecology, behavior and bionomics body size, symmetry and courtship behavior of dysdercus maurus distant (Hemiptera: Pyrrhocoridae). Neotropical Entomology 40:305-311. DOI: 10.1590/S1519-566X2011000300003.

Kelly SP, Cuevas E, Ramírez A. 2015. Stable isotope analyses of web-spinning spider assemblages along a headwater stream in Puerto Rico. PeerJ 3:e1324. DOI: $10.7717 /$ peerj. 1324 .

Klem CC, Gutiérrez-Fonseca PE. 2017. CO2-driven experimental acidification effects on aquatic macroinvertebrates in a tropical stream. Journal of Freshwater Ecology 32:195-204. DOI: 10.1080/02705060.2016.1259126.

Lancaster J. 1999. Small-scale movements of lotic macroinvertebrates with variations in flow. Freshwater Biology 41:605-619. DOI: 10.1046/j.1365-2427.1999.00410.x.

Lancaster J, Hildrew AG. 1993. Flow refugia and the microdistribution of lotic macroinvertebrates. Journal of the North American Benthological Society 12:385-393. DOI: $10.2307 / 1467619$.

Lytle DA. 2002. Flash floods and aquatic insect life-history evolution: Evaluation of multiple models. Ecology 83:370-385. DOI: 10.1890/0012-9658(2002)083[0370:FFAAIL]2.0.CO;2. Malison RL, Benjamin JR, Baxter C V. 2010. Measuring adult insect emergence from streams: 
530

531

532

533

534

535

536

537

538

539

540

541

542

543

544

545

546

547

548

549

550

551

552

553

554

555

556

557

558

559

560

the influence of trap placement and a comparison with benthic sampling. Journal of Norht American Benthological Society 2. DOI: 10.1899/09-086.1.

Masteller EC. 1993. Comparison of tropical and temperate emergence phenology of aquatic insects from Puerto Rico and Pennsylvania. Journal of the Kansas Entomological Society 66:192-199.

Mazerolle MJ. 2019. AICcmodavg: Model selection and multimodel inference based on (Q)AIC(c). :https://cran.r-project.org/web/packages/AICcmodavg.

Merkley SS, Rader RB, Schaalje GB. 2015. Introduced Western Mosquitofish (Gambusia affinis) reduce the emergence of aquatic insects in a desert spring. Freshwater Science 34:564-573. DOI: 10.1086/680381.

Molineri C. 2010. The influence of floods on the life history of dominant mayflies (Ephemeroptera) in a subtropical mountain stream. Studies on Neotropical Fauna and Environment 45:149-157. DOI: 10.1080/01650521.2010.524107.

Møller AP. 1990. Fluctuating asymmetry in male sexual ornaments may reliably reveal male quality. Animal Behaviour 40:1185-1187. DOI: 10.1016/S0003-3472(05)80187-3.

Moore JW, Schindler DE. 2010. Spawning salmon and the phenology of emergence in stream insects. Proceedings of the Royal Society B: Biological Sciences 277:1695-1703. DOI: 10.1098/rspb.2009.2342.

Mpho M, Holloway GJ, Callaghan A. 2001. A comparison of the effects of organophosphate insecticide exposure and temperature stress on fluctuating asymmetry and life history traits in Culex quinquefasciatus. Chemosphere 45:713-720.

Nakano S, Murakami M. 2001. Reciprocal subsidies: Dynamic interdependence between terrestrial and aquatic food webs. Proceedings of the National Academy of Sciences 98:166170.

Nosil P, Reimchen TE. 2007. Tarsal asymmetry, nutritional condition, and survival in water boatmen (Callicorixa vulnerata). Evolution 55:712-720. DOI: 10.1111/j.00143820.2001.tb00807.x.

O’Brien RM. 2007. A caution regarding rules of thumb for variance inflation factors. Quality and Quantity 41:673-690. DOI: 10.1007/s11135-006-9018-6.

O'Gorman PA, Schneider T. 2009. The physical basis for increases in precipitation extremes in simulations of 21 st-century climate change. Proceedings of the National Academy of 
561

562

563

564

565

566

567

568

569

570

571

572

573

574

575

576

577

578

579

580

581

582

583

584

585

586

587

588

589

590

591

Sciences 106:14773-14777.

Palmer AR. 1994. Fluctuating asymmetry analyses: A primer. In: Markow TA ed. Developmental Instability: Its Origins and Evolutionary Implications. Kluwer, Dordrecht, Netherlands: Kluwer, Dordrecht, Netherlands., 335-364.

Palmer AR, Strobeck C. 1986. Fluctuating Asymmetry: Measurement, Analysis, Patterns. Annual Review of Ecology and Systematics 17:391-421.

Palmer AR, Strobeck C. 1992. Fluctuating asymmetry as a measure of developmental stability: implications of non-normal distributions and power of statistical tests. Acta Zoologica Fennica 191:57-72.

Palmer AR, Strobeck C. 2003. Fluctuating asymmetry analyses revisited. In: Polak M ed. Developmental instability. causes and consequences. New York: Oxford, 279-319.

Peckarsky BL, Taylor BW, McIntosh AR, McPeek MA, Lytle DA. 2001. Variation in mayfly size at metamorphosis as a developmental response to risk of predation. Ecology 82:740757. DOI: 10.1890/0012-9658(2001)082[0740:VIMSAM]2.0.CO;2.

Pescador ML, Masteller EC, Buzby KM. 1993. Composition and phenology of Ephemeroptera from a tropical rainforest stream at El Verde, Puerto Rico. Journal of the Kansas Entomological Society 66:151-159.

Pinto N, Juen L, Cabette H, De Marco Jr P. 2012. Fluctuating asymmetry and wing size of Argia tinctipennis Selys (Zygoptera: Coenagrionidae) in relation to riparian forest preservation status. Neotropical Entomology 41:178-185. DOI: 10.1007/s13744-012-0029-9.

Poepperl R. 2000a. The filter feeders Hydropsyche angustipennis and H. pellucidula (Trichoptera: Hydropsychidae) in a Northern German lowland stream: Microdistribution, larval development, emergence pattern, and secondary production. Limnologica 30:65-72. DOI: $10.1016 / \mathrm{S} 0075-9511(00) 80046-8$.

Poepperl R. 2000b. Benthic secondary production and biomass of insects emerging from a northern German temperate stream. Freshwater Biology 44:199-211. DOI: 10.1046/j.13652427.2000.00558.x.

Power ME, Stout RJ, Cushing CE, Harper PP, Hauer FR, Matthews6 WJ, Moyle PB, Statzner B, Wais De Badgen IR. 1988. Biotic and abiotic controls in river and stream communities.

Pritchard G. 1996. The life history of a tropical dragonfly: Cora marina (Odonata: Polythoridae) in Guanacaste, Costa Rica. Journal of Tropical Ecology 12:573-581. DOI: 
592

593

594

595

596

597

598

599

600

601

602

603

604

605

606

607

608

609

610

611

612

613

614

615

616

617

618

619

620

621

622

$10.1017 / \mathrm{S} 0266467400009792$.

R Core Team. 2019. R: A Language and Environment for Statistical Computing. R Foundation for Statistical Computing. Vienna, Austria. http://www.R-project.org/.

Ramírez A, Pringle CM. 1998. Structure and production of a benthic insect assemblage in a Neotropical stream. Journal of the North American Benthological Society 17:443-463. DOI: $10.2307 / 1468365$.

Ramírez A, Pringle CM, Douglas M. 2006. Temporal and spatial patterns in stream physicochemistry and insect assemblages in tropical lowland streams. Journal of the North American Benthological Society 25:108-123. DOI: 10.1899/08873593(2006)25[108:taspis]2.0.co;2.

Rapp AD, Peterson AG, Frauenfeld OW, Quiring SM, Roark EB. 2014. Climatology of storm characteristics in Costa Rica using the TRMM precipitation radar. Journal of Hydrometeorology 15:2615-2633. DOI: 10.1175/JHM-D-13-0174.1.

Regester KJ, Lips KR, Whiles MR. 2006. Energy flow and subsidies associated with the complex life cycle of ambystomatid salamanders in ponds and adjacent forest in southern Illinois. Oecologia 147:303-314. DOI: 10.1007/s00442-005-0266-2.

Resh VH, Brown A V, Covich AP, Gurtz ME, Li HW, Minshall GW, Reice SR, Sheldon AL, Wallace JB, Wissmar RC. 1988. The role of disturbance in stream ecology. Journal of the North American Benthological Society 7:433-455. DOI: 10.2307/1467300.

Ríos-Touma B, Encalada AC, Prat Fornells N. 2011. Macroinvertebrate assemblages of an Andean high-altitude tropical stream: the importance of season and flow. International Review of Hydrobiology 96:667-685. DOI: 10.1002/iroh.201111342.

Sabo JL, Bastow JL, Power ME. 2002. Length-mass relationships for adult aquatic and terrestrial invertebrates in a California watershed. Journal of the North American Benthological Society 21:336-343. DOI: 10.2307/1468420.

Sánchez-Murillo R, Durán-Quesada AM, Birkel C, Esquivel-Hernández G, Boll J. 2017. Tropical precipitation anomalies and d-excess evolution during El Niño 2014-16. Hydrological Processes 31:956-967. DOI: 10.1002/hyp.11088.

Sanford JRL, Paaby P, Luvall JC, Phillips E. 1994. Climate, geomorphology, and aquatic systems. La Selva : ecology and natural history of a neotropical rain forest:19-33.

Santos M. 2001. Fluctuating asymmetry is nongenetically related to mating success in 
623

624

625

626

627

628

629

630

631

632

633

634

635

636

637

638

639

640

641

642

643

644

645

646

647

648

649

650

651

652

653

Drosophila buzzatii. Evolution 55:2248-2256. DOI: 10.1111/j.0014-3820.2001.tb00739.x.

Segura MO, Siqueira T, Fonseca-Gessner AA. 2013. Variation in body size of Phanocerus clavicornis Sharp, 1882 (Coleoptera: Elmidae: Larainae) in Atlantic Rainforest streams in response to hydraulic disturbance. Brazilian Journal of Biology 73:747-752. DOI: 10.1590/S1519-69842013000400010.

Small GE, Ardón M, Jackman AP, Duff JH, Triska FJ, Ramírez A, Snyder M, Pringle CM. 2012. Rainfall-Driven Amplification of Seasonal Acidification in Poorly Buffered Tropical Streams. Ecosystems 15:974-985. DOI: 10.1007/s10021-012-9559-6.

Small GE, Duff JH, Torres PJ, Pringle CM. 2013a. Insect emergence as a nitrogen flux in Neotropical streams: Comparisons with microbial denitrification across a stream phosphorus gradient. Freshwater Science 32:1178-1187. DOI: 10.1899/12-084.1.

Small GE, Torres PJ, Schweizer LM, Duff JH, Pringle CM. 2013b. Importance of terrestrial arthropods as subsidies in lowland Neotropical rain forest stream ecosystems. Biotropica 45:80-87. DOI: 10.1111/j.1744-7429.2012.00896.x.

Statzner B, Resh VH. 1993. Multiple-site and-year analyses of stream insect emergence: a test of ecological theory. Oecologia 96:65-79. DOI: 10.1007/BF00318032.

Sweeney BW, Jackson JK, Funk DH. 1995. Semivoltinism, seasonal emergence, and adult size variation in a tropical stream mayfly (Euthyplocia hecuba). Journal of the North American Benthological Society 14:131-146. DOI: 10.2307/1467729.

Townsend CR, Dolédec S, Scarsbrook MR. 1997. Species traits in relation to temporal and spatial heterogeneity in streams: a test of habitat templet theory. Freshwater Biology 37:367-387. DOI: 10.1046/j.1365-2427.1997.00166.x.

Vásquez D, Flowers RW, Springer M. 2009. Life history of five small minnow mayflies (Ephemeroptera: Baetidae) in a small tropical stream on the Caribbean slope of Costa Rica. Aquatic Insects 31:319-332. DOI: 10.1080/01650420903083096.

Warmbold JW, Wesner JS. 2018. Predator foraging strategy mediates the effects of predators on local and emigrating prey. Oikos 127:579-589. DOI: 10.1111/oik.04676.

Whiles MR, Goldowitz BS. 2001. Hydrologic influences on insect emergence production from central Platte River Wetlands. Ecological Applications 11:1829-1842. DOI: 10.1890/10510761(2001)011[1829:HIOIEP]2.0.CO;2.

Whiles MR, Goldowitz BS, Charlton RE. 1999. Life history and production of a semi-terrestrial 
654 Limnephilid caddisfly in an intermittent Platte river wetland. Journal of the North American 655 Benthological Society 18:533-544. DOI: 10.2307/1468385.

656 Wickham H. 2016. ggplot2: Elegant graphics for data analysis. New York: Springer-Verlag.

657 Yuen EYL, Dudgeon D. 2016. The magnitude and seasonality of aquatic insect subsidies to 658 tropical stream riparia in Hong Kong. Aquatic Sciences 78:655-667. DOI: 10.1007/s00027$659 \quad 015-0455-\mathrm{y}$.

660 
Figure 1

Temporal variability of precipitation in 2002 and 2003 (A), and relationship between mean monthly precipitation and discharge (B). Grey shaded area represents the $95 \%$ confidence intervals.

A

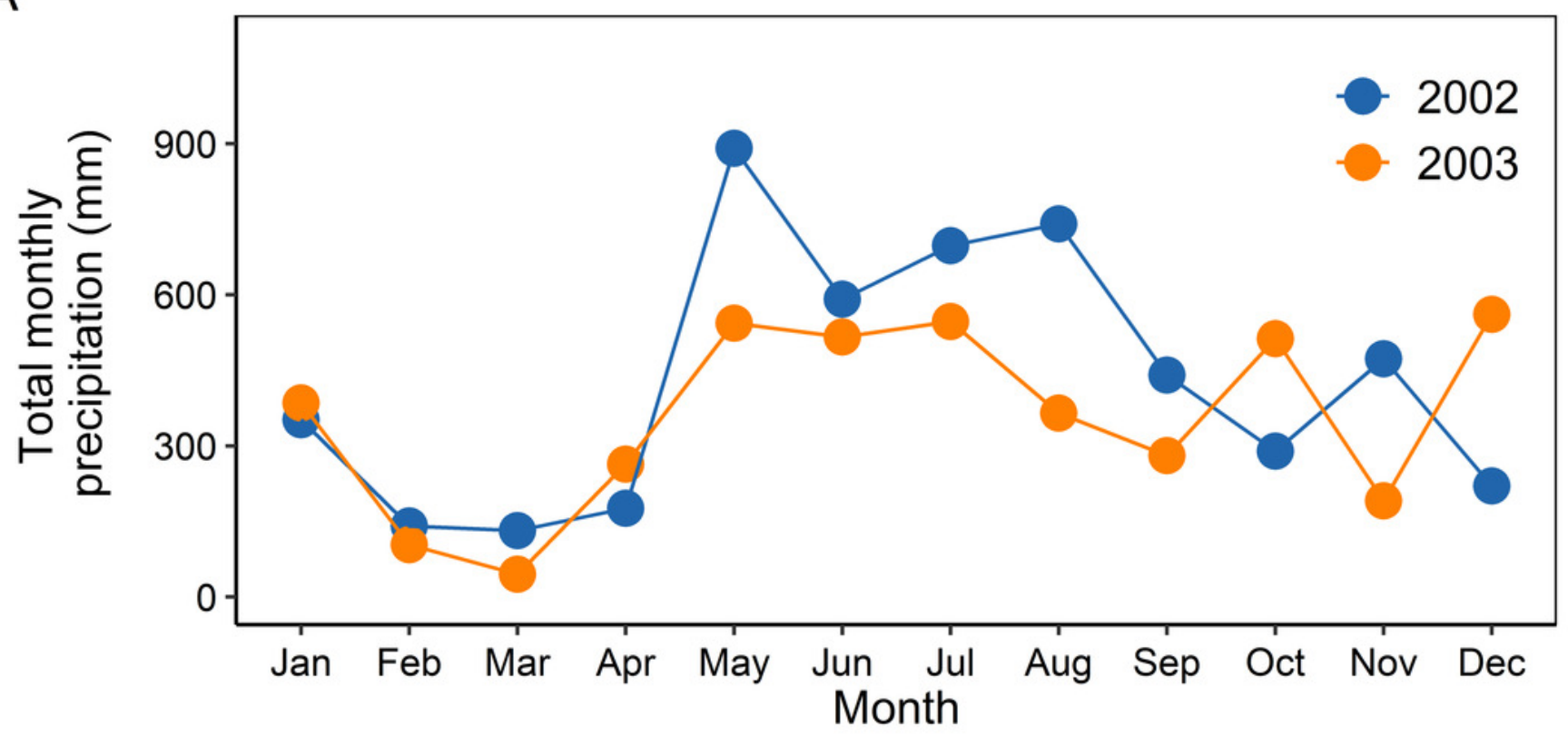

B

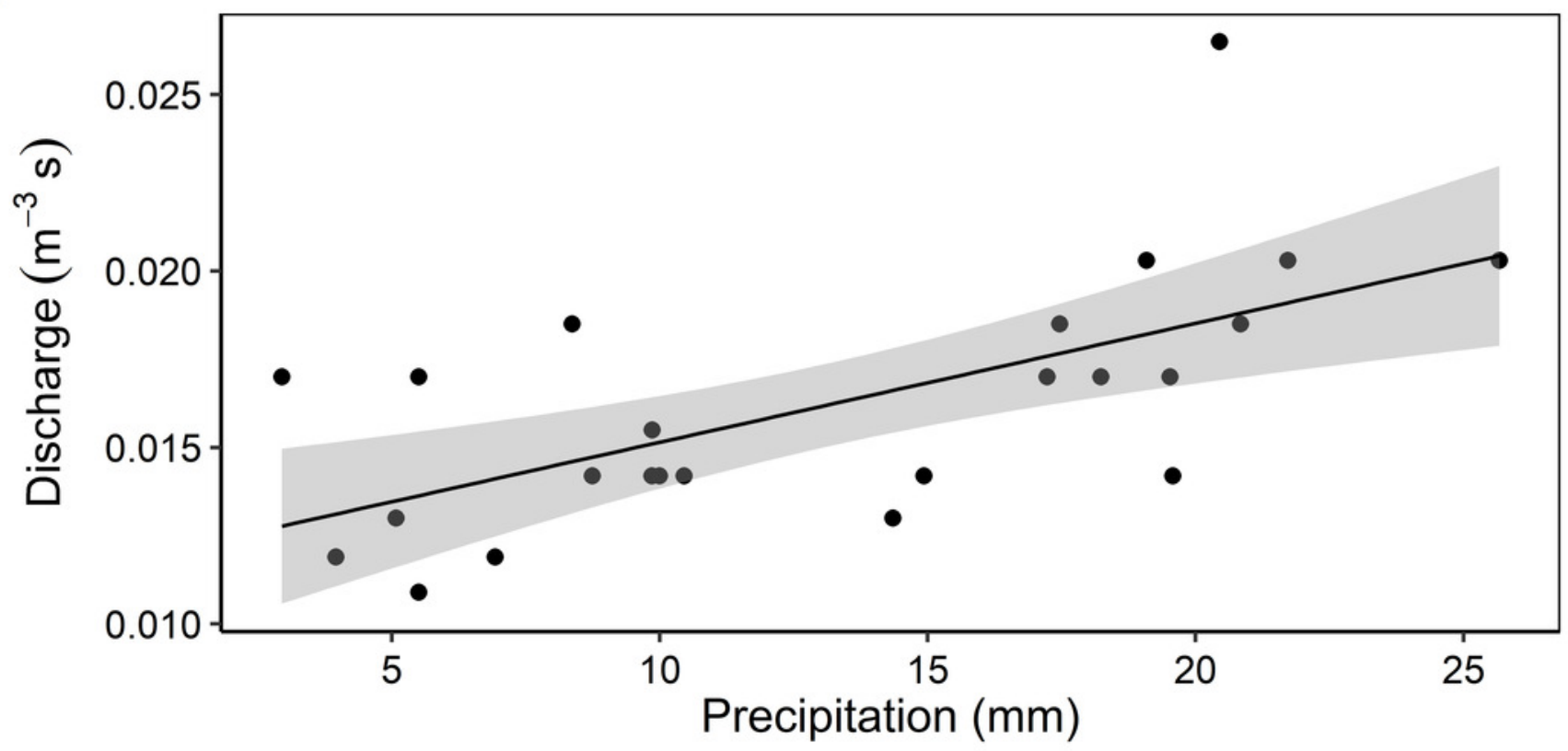


Figure 2

Temporal variability of benthic and emerging adult biomass during (A) 2002 and (B) 2003.

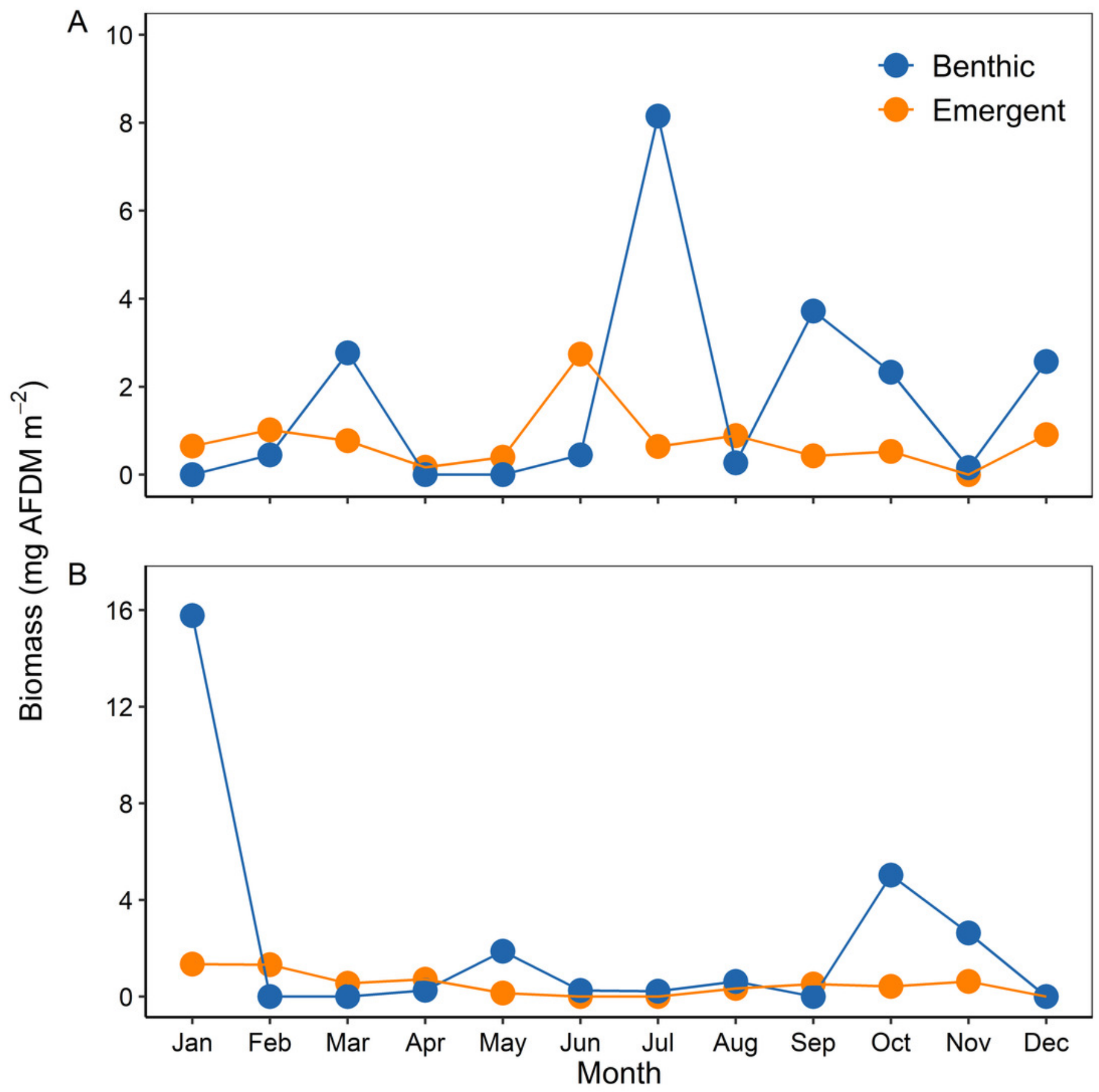


Figure 3

Body length variability of $F$. caribbianus and precipitation.

Relationship between $F$. caribbianus body length and average precipitation in the 159 days prior to the sampling date. Each point represents an individual, including males and females. Gray shaded area represents the $95 \%$ confidence intervals.

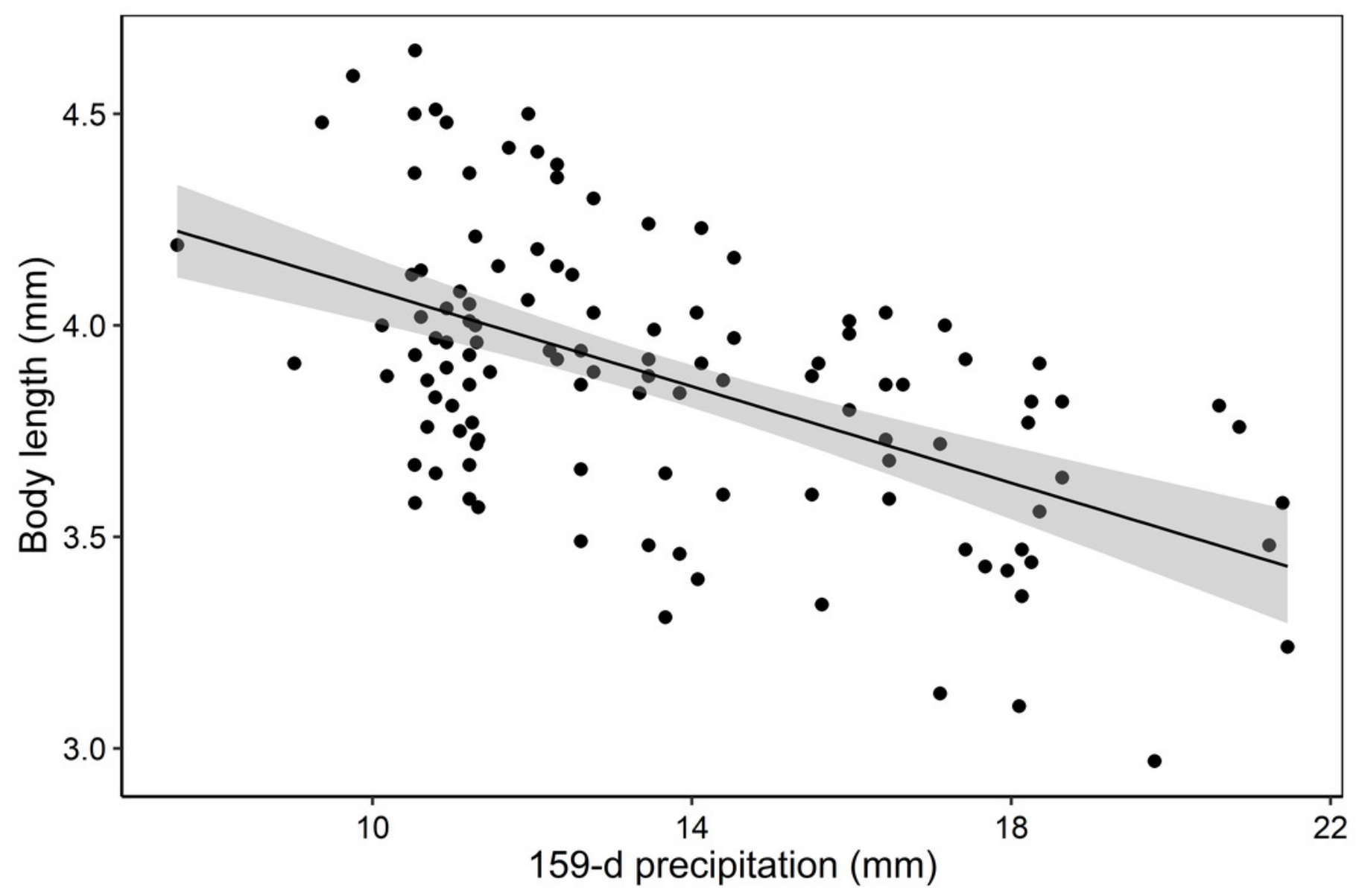




\section{Table 1 (on next page)}

Test for normality and $t$-test for each trait. AFW: forewing area, LFW: forewing length; SF: length of the second segment of forceps. 
1

2

\begin{tabular}{llccccccc}
\hline & Trait & N & $\begin{array}{c}\text { Mean } \\
\text { (R-L) }\end{array}$ & SE & \multicolumn{2}{c}{ Normality test } & \multicolumn{2}{c}{ t-tests } \\
\cline { 6 - 9 } & & & & & & & & \\
\hline Male & & & & & & P-Value & $\boldsymbol{t}$ & P-Value \\
& AFW & 31 & 0.00 & 0.082 & 0.975 & 0.685 & 0.065 & 0.984 \\
& LFW & 33 & -0.013 & 0.083 & 0.969 & 0.473 & -0.924 & 0.363 \\
& SF & 30 & -0.004 & 0.016 & 0.955 & 0.235 & -1.453 & 0.157 \\
\hline Female & & & & & & & & \\
& AFW & 28 & 0.028 & 0.077 & 0.981 & 0.862 & 1.958 & 0.061 \\
& LFW & 40 & 0.007 & 0.023 & 0.956 & 0.120 & 2.015 & 0.051 \\
\hline
\end{tabular}

3 


\section{Table 2 (on next page)}

Result of the two-way mixed model ANOVAs performed for each trait with Side as a Fixed component and Individual as Random component.

Indices of asymmetry: FA1, FA4a, FA10a and measurement error as percentage (ME3 as \% of $\mathrm{ME}_{\mathrm{Sxl}}$ ). AFW: forewing area, LFW: forewing length, SF: length of the second segment of forceps.

${ }^{*} \mathrm{p}<0.05 ;{ }^{a}$ mean of the standard deviation of triplicate measurements on the right and left sides (i.e., indicator of accuracy during photo measurement); ${ }^{b}$ mean of the right and left side measurements; ${ }^{c}$ mean squared of the side $x$ individual interaction; ${ }^{d}$ mean squared of the variance of the repeated measurements. 


\begin{tabular}{|c|c|c|c|c|c|c|c|c|c|c|c|c|c|c|c|}
\hline \multirow[t]{2}{*}{ Trait } & \multirow[t]{2}{*}{$\mathrm{N}$} & \multirow{2}{*}{$\begin{array}{l}\text { Mean } \\
\text { error }^{\text {a }}\end{array}$} & \multirow{2}{*}{$\begin{array}{l}\text { Mean } \\
(\mathrm{mm})^{\mathrm{b}}\end{array}$} & \multicolumn{2}{|c|}{ Side } & \multicolumn{2}{|c|}{ Individual } & \multicolumn{3}{|c|}{ Side $x$ Individual } & \multirow[t]{2}{*}{$\mathrm{ME}_{\text {error }}{ }^{\mathrm{d}}$} & \multirow[t]{2}{*}{ FA1 } & \multirow[t]{2}{*}{ FA4a } & \multirow[t]{2}{*}{ FA10a } & \multirow{2}{*}{$\begin{array}{c}\text { ME3 } \\
(\%)\end{array}$} \\
\hline & & & & df & $\mathrm{F}$ & $\mathrm{df}$ & $\mathrm{F}$ & $\mathrm{df}$ & $M E_{S x I}{ }^{c}$ & $\mathrm{~F}$ & & & & & \\
\hline \multicolumn{16}{|l|}{ Male } \\
\hline AFW & 31 & 0.03 & 4.41 & 1 & $18.90 *$ & 30 & $797.40 *$ & 30 & $3.98 \mathrm{e}-5$ & $13.30 *$ & $2.99 \mathrm{e}-6$ & 0.076 & 0.088 & 0.004 & 16.4 \\
\hline LFW & 30 & 0.03 & 3.79 & 1 & 2.05 & 29 & $223.89 *$ & 29 & $3.33 \mathrm{e}-3$ & $5.10^{*}$ & $6.52 \mathrm{e}-4$ & 0.063 & 0.066 & 0.034 & 19.6 \\
\hline SF & 30 & 0.006 & 0.45 & 1 & $10.70 *$ & 29 & $103.80 *$ & 29 & $4.25 \mathrm{e}-4$ & $7.50 *$ & $5.67 e-5$ & 0.012 & 0.013 & 0.012 & 13.3 \\
\hline \multicolumn{16}{|l|}{ Female } \\
\hline AFW & 28 & 0.03 & 5.16 & 1 & 0.01 & 27 & $2163.2 *$ & 27 & $1.38 \mathrm{e}-5$ & $16.9 *$ & $8.27 \mathrm{e}-7$ & 0.065 & 0.062 & 0.002 & 5.9 \\
\hline LFW & 28 & 0.02 & 4.01 & 1 & $8.66^{*}$ & 27 & $507.30 *$ & 27 & $2.35 \mathrm{e}-3$ & $5.20 *$ & $4.51 \mathrm{e}-4$ & 0.043 & 0.046 & 0.028 & 19.2 \\
\hline
\end{tabular}

